\title{
Development and Validation of Statistical Models of Femur Geometry for Use with Parametric Finite Element Models
}

\author{
Katelyn F. Klein \\ Jingwen $\mathrm{Hu}$ \\ Matthew P. Reed \\ Carrie N. Hoff \\ Jonathan D. Rupp
}

November 2015

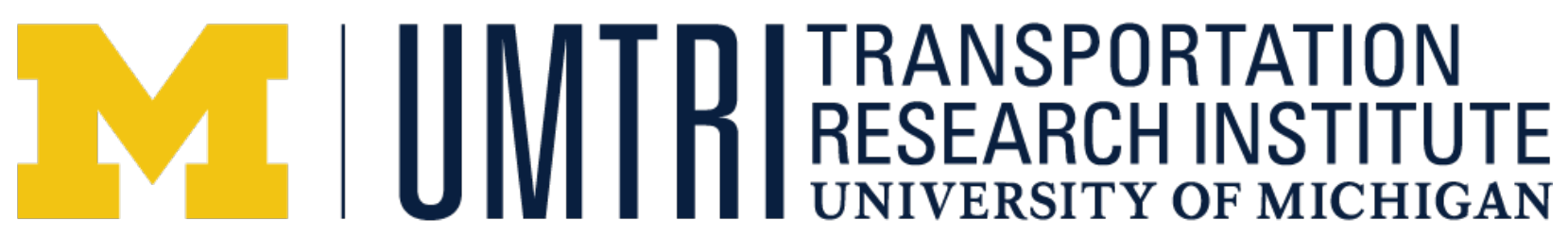




\title{
Development and Validation of Statistical Models of Femur Geometry for Use
} with Parametric Finite Element Models

\author{
Katelyn F. Klein \\ Jingwen $\mathrm{Hu}$ \\ Matthew P. Reed \\ Carrie N. Hoff \\ Jonathan D. Rupp
}

The University of Michigan

Transportation Research Institute

Ann Arbor, MI 48109-2150

U.S.A.

November 2015 
Technical Report Documentation Page

\begin{tabular}{|c|c|c|}
\hline $\begin{array}{l}\text { 1. Report No. } \\
\text { UMTRI-2015-37 }\end{array}$ & \multicolumn{2}{|c|}{ 3. Recipient's Catalog No. } \\
\hline \multirow{2}{*}{$\begin{array}{l}\text { 4. Title and Subtitle } \\
\text { Development and Validation of Statistical Models of Femur } \\
\text { Geometry for Use with Parametric Finite Element Models }\end{array}$} & \multicolumn{2}{|c|}{$\begin{array}{l}\text { 5. Report Date } \\
\text { November } 2015\end{array}$} \\
\hline & \multicolumn{2}{|c|}{$\begin{array}{l}\text { 6. Performing Organization Code } \\
063908\end{array}$} \\
\hline $\begin{array}{l}\text { 7. Author(s) } \\
\text { Klein, K. F., Hu, J., Reed, M. P., Hoff, C. N., and Rupp, J. D. }\end{array}$ & \multicolumn{2}{|c|}{$\begin{array}{l}\text { 8. Performing Organization Report No. } \\
\text { UMTRI-2015-37 }\end{array}$} \\
\hline \multirow{2}{*}{$\begin{array}{l}\text { 9. Performing Organization Name and Address } \\
\text { The University of Michigan } \\
\text { Transportation Research Institute } \\
\text { 2901 Baxter Road } \\
\text { Ann Arbor, Michigan 48109-2150 U.S.A. }\end{array}$} & \multicolumn{2}{|c|}{ 10. Work Unit no. (TRAIS) } \\
\hline & \multicolumn{2}{|c|}{ 11. Contract or Grant No. } \\
\hline \multirow{2}{*}{$\begin{array}{l}\text { 12. Sponsoring Agency Name and Address } \\
\text { U.S. Department of Transportation } \\
\text { National Highway Traffic Safety Administration } \\
1200 \text { New Jersey Avenue, SE } \\
\text { Washington, DC } 20590\end{array}$} & \multicolumn{2}{|c|}{ 13. Type of Report and Period Covered } \\
\hline & \multicolumn{2}{|c|}{ 14. Sponsoring Agency Code } \\
\hline \multicolumn{3}{|l|}{ 15. Supplementary Notes } \\
\hline \multicolumn{3}{|c|}{$\begin{array}{l}\text { 16. Abstract } \\
\text { Statistical models from a previous study that predict male and female femur geometry as } \\
\text { functions of age, body mass index (BMI), and femur length were updated as part of an effort to } \\
\text { develop lower-extremity finite element models with geometries that are parametric with subject } \\
\text { characteristics. The process for updating these models involved extracting femur geometry } \\
\text { from clinical CT scans of an additional } 8 \text { men and } 36 \text { women (previous models used CT scans } \\
\text { from } 62 \text { men and } 36 \text { women for a new total of } 70 \text { men and } 72 \text { women), using all of the scans for } \\
\text { fitting a template finite element femur mesh to the surface geometry of each patient, and then } \\
\text { programmatically determining thickness at each nodal location. Principal component analysis } \\
\text { was then performed on the thickness and geometry nodal coordinates, and linear regression } \\
\text { models were developed to predict principal component scores as functions of age, BMI, and } \\
\text { femur length. The results from the updated models were compared to the previous study, and } \\
\left.\text { the only improvement was in the } \mathrm{R}^{2} \text { value for the female models ( } 0.74 \text { to } 0.82\right) \text {. The largest } \\
\text { differences between the original models and the previous models occurred in the ends of the } \\
\text { femur, where the largest errors in model predictions occurred. }\end{array}$} \\
\hline $\begin{array}{l}\text { 17. Key Words } \\
\text { Principal component analysis, Regression, Biomechanics, Motor- } \\
\text { vehicle crashes, Lower-extremity injury, Subject characteristics. }\end{array}$ & $\begin{array}{l}\text { 18. Distribution St } \\
\text { Unlimited }\end{array}$ & \\
\hline \begin{tabular}{l|l} 
19. Security Classification (of this report) & 20. Security Classification (of this page) \\
None & None
\end{tabular} & $\begin{array}{c}\text { 21. No. of Pages } \\
25\end{array}$ & 22. Price \\
\hline
\end{tabular}


SI* (MODERN METRIC) CONVERSION FACTORS

APPROXIMATE CONVERSIONS TO SI UNITS

\begin{tabular}{|c|c|c|c|c|}
\hline Symbol & When You Know & Multiply By & To Find & Symbol \\
\hline \multicolumn{5}{|c|}{ LENGTH } \\
\hline in & inches & 25.4 & millimeters & $\mathrm{mm}$ \\
\hline $\mathrm{ft}$ & feet & 0.305 & meters & $\mathrm{m}$ \\
\hline yd & yards & 0.914 & meters & $\mathrm{m}$ \\
\hline & miles & 1.61 & kilometers & $\mathrm{km}$ \\
\hline \multicolumn{5}{|c|}{ AREA } \\
\hline $\mathrm{in}^{2}$ & square inches & 645.2 & square millimeters & $\mathrm{mm}^{2}$ \\
\hline $\mathrm{ft}^{2}$ & square feet & 0.093 & square meters & $\mathrm{m}^{2}$ \\
\hline$y d^{2}$ & square yard & 0.836 & square meters & $\mathrm{m}^{2}$ \\
\hline ac & acres & 0.405 & hectares & ha \\
\hline $\mathrm{mi}^{2}$ & square miles & 2.59 & square kilometers & $\mathrm{km}^{2}$ \\
\hline \multicolumn{5}{|c|}{ VOLUME } \\
\hline $\mathrm{fl} \mathrm{oz}$ & fluid ounces & 29.57 & milliliters & $\mathrm{mL}$ \\
\hline gal & gallons & 3.785 & liters & L \\
\hline $\mathrm{ft}^{3}$ & cubic feet & 0.028 & cubic meters & $\mathrm{m}^{3}$ \\
\hline & cubic yards & 0.765 & cubic meters & \\
\hline \multicolumn{5}{|c|}{ NOTE: volumes greater than $1000 \mathrm{~L}$ shall be shown in $\mathrm{m}^{3}$} \\
\hline \multicolumn{5}{|c|}{ MASS } \\
\hline $\mathrm{Oz}$ & ounces & 28.35 & grams & $\mathrm{g}$ \\
\hline $\mathrm{lb}$ & pounds & 0.454 & kilograms & $\mathrm{kg}$ \\
\hline $\mathrm{T}$ & short tons (2000 lb) & 0.907 & megagrams (or "metric ton") & $\mathrm{Mg}$ (or "t") \\
\hline \multicolumn{5}{|c|}{ TEMPERATURE (exact degrees) } \\
\hline${ }^{\circ} \mathrm{F}$ & Fahrenheit & $\begin{array}{r}5(\mathrm{~F}-32) / 9 \\
\text { or }(\mathrm{F}-32) / 1\end{array}$ & Celsius & ${ }^{\circ} \mathrm{C}$ \\
\hline \multicolumn{5}{|c|}{ ILLUMINATION } \\
\hline fc & foot-candles & 10.76 & lux & \\
\hline $\mathrm{fl}$ & foot-Lamberts & 3.426 & candela $/ \mathrm{m}^{2}$ & $\mathrm{~cd} / \mathrm{m}^{2}$ \\
\hline \multicolumn{5}{|c|}{ FORCE and PRESSURE or STRESS } \\
\hline & poundforce & 4.45 & newtons & $\mathrm{N}$ \\
\hline $\mathrm{lbf} / \mathrm{in}^{2}$ & poundforce per square inch & 6.89 & kilopascals & $\mathrm{kPa}$ \\
\hline \multicolumn{5}{|c|}{ APPROXIMATE CONVERSIONS FROM SI UNITS } \\
\hline Symbol & When You Know & Multiply By & To Find & Symbol \\
\hline \multicolumn{5}{|c|}{ LENGTH } \\
\hline $\mathrm{mm}$ & millimeters & 0.039 & inches & in \\
\hline $\mathrm{m}$ & meters & 3.28 & feet & $\mathrm{ft}$ \\
\hline $\mathrm{m}$ & meters & 1.09 & yards & yd \\
\hline $\mathrm{km}$ & kilometers & 0.621 & miles & mi \\
\hline \multicolumn{5}{|c|}{ AREA } \\
\hline $\mathrm{mm}^{2}$ & square millimeters & 0.0016 & square inches & $i^{2}$ \\
\hline $\mathrm{m}^{2}$ & square meters & 10.764 & square feet & $\mathrm{ft}^{2}$ \\
\hline $\mathrm{m}^{2}$ & square meters & 1.195 & square yards & $y d^{2}$ \\
\hline ha & hectares & 2.47 & acres & ac \\
\hline $\mathrm{km}^{2}$ & square kilometers & 0.386 & square miles & $\mathrm{mi}^{2}$ \\
\hline \multicolumn{5}{|c|}{ VOLUME } \\
\hline $\mathrm{mL}$ & milliliters & 0.034 & fluid ounces & $\mathrm{fl} \mathrm{oz}$ \\
\hline L & 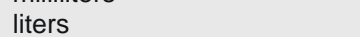 & 0.264 & gallons & gal \\
\hline $\mathrm{m}^{3}$ & cubic meters & 35.314 & cubic feet & $\mathrm{ft}^{3}$ \\
\hline $\mathrm{m}^{3}$ & cubic meters & 1.307 & cubic yards & $y d^{3}$ \\
\hline \multicolumn{5}{|c|}{ MASS } \\
\hline g & grams & 0.035 & ounces & $\mathrm{Oz}$ \\
\hline $\mathrm{kg}$ & kilograms & 2.202 & pounds & $\mathrm{lb}$ \\
\hline Mg (or "t") & megagrams (or "metric ton") & 1.103 & short tons (2000 lb) & $T$ \\
\hline \multicolumn{5}{|c|}{ TEMPERATURE (exact degrees) } \\
\hline${ }^{\circ} \mathrm{C}$ & Celsius & $1.8 \mathrm{C}+3$ & Fahrenheit & ${ }^{\circ} \mathrm{F}$ \\
\hline \multicolumn{5}{|c|}{ ILLUMINATION } \\
\hline & lux & 0.0929 & foot-candles & fc \\
\hline $\mathrm{cd} / \mathrm{m}^{2}$ & candela $/ \mathrm{m}^{2}$ & 0.2919 & foot-Lamberts & $\mathrm{fl}$ \\
\hline \multicolumn{5}{|c|}{ FORCE and PRESSURE or STRESS } \\
\hline $\mathrm{N}$ & newtons & 0.225 & poundforce & \\
\hline $\mathrm{kPa}$ & kilopascals & 0.145 & poundforce per square inch & $\mathrm{lbf} / \mathrm{in}^{2}$ \\
\hline
\end{tabular}

*SI is the symbol for the International System of Units. Appropriate rounding should be made to comply with Section 4 of ASTM E380. (Revised March 2003) 


\section{Contents}

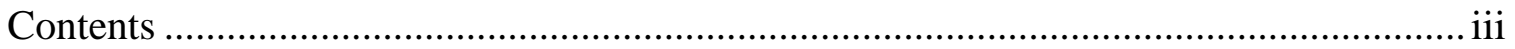

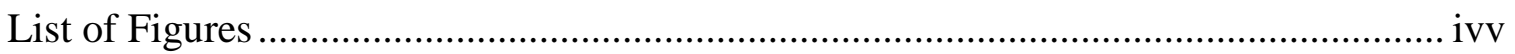

List of Tables ............................................................................................... iv

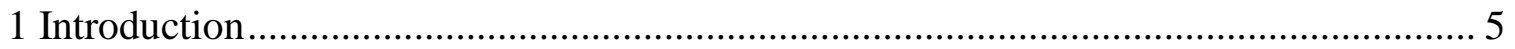

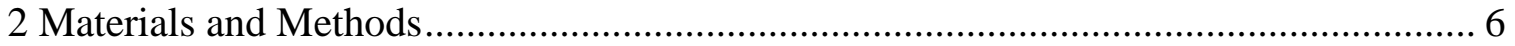

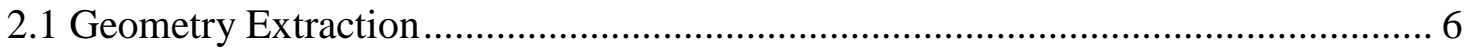

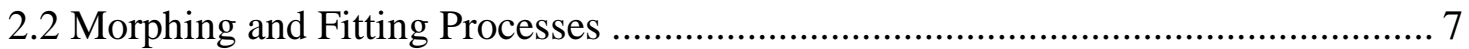

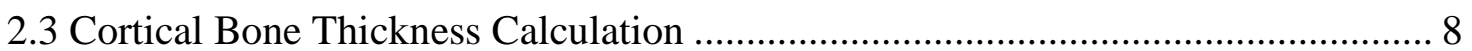

2.4 Principal Component Analysis and Regression............................................... 8

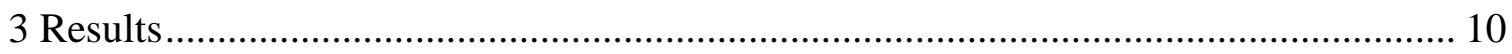

3.1 Principal Component Analysis and Regression.............................................. 10

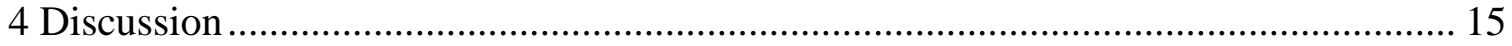

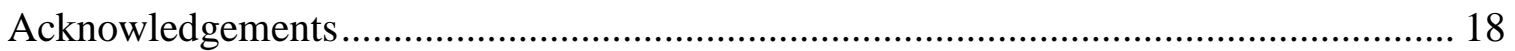

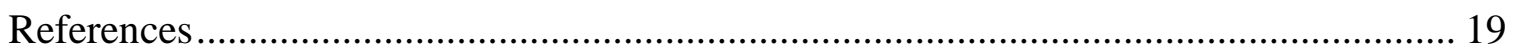




\section{List of Figures}

Figure 1. Distributions of subject characteristics.

Figure 2. Femur length defined as the distance along the long axis of the femur (determined from anatomic landmark locations in the landmarking process) between the most superior point on the femoral head and most inferior point on the femoral condyles.7 Figure 3. The morphing and fitting processes of a template femur FE mesh onto an example extracted bone surface geometry.

Figure 4. The five area locations (1-5) along the shaft of the femur used for cortical bone area measurements.

Figure 5. Distribution of average and $95^{\text {th }}$ percentile absolute errors in nodal coordinate locations (left two columns) and cortical thickness values at nodal locations (right two columns) between the actual data and predicted geometries.

Figure 6. Cortical bone cross-sectional areas at five locations along the shafts of the PMHS femurs and the errors in the predicted shaft cross-sectional areas.

Figure 7. Minimum, mean, and maximum distributions of nodal coordinate distance errors (top) and differences in thickness values (bottom) between original predicted femurs and updated predicted femurs using Ivarsson et al. ${ }^{11}$ study characteristics

\section{List of Tables}

Table 1a. $p$-values of predictors in the female and male external geometry models........10

Table 1b. $p$-values of predictors in the female and male thickness models......................10 


\section{Introduction}

Elderly, female, and occupants with higher body mass index (BMI) are at increased risk of lower-extremity injuries in frontal crashes compared to younger, male, and leaner individuals ${ }^{7,21,28,29}$. These effects may be due to differences in lowerextremity skeletal geometry and material properties as well as pre-crash posture of the lower extremities. Evaluating the importance of these effects, and using the resulting knowledge to design improved safety devices to protect vulnerable occupants in motor-vehicle crashes, requires simultaneously considering the effects of subject characteristics, body geometry, body material properties, and occupant posture. Such factors are most efficiently considered using tests with finite element (FE) models, and in particular simulations with FE models that have geometry, material properties, and posture that are parameterized with respect to occupant characteristics. However, most current FE human models represent occupants who are one of the three adult size categories for which crash test dummies are available, i.e., the midsize male, small female, and large male ${ }^{10}$.

The few parametric FE models, or models that are parameterized with occupant characteristics, that have been developed either are of body regions other than the lower extremities or lack the fidelity that is needed to characterize how occupant characteristics affect bone cross-sectional geometry ${ }^{2,8,17-19,30}$. Previous FE models of the lower extremities that have parametric geometry have focused mainly on the proximal femur, and are intended to predict the risk of femur fracture in falls or for use in implant biomechanics ${ }^{4,5,16,23}$. These models are parameterized with variables such as femur dimensions, and not parameterized with subject characteristics, such as BMI, that are known to be important for vehicle crash safety assessment, and do not cover the needed range of population characteristics. However, previous studies demonstrate that skeletal geometry is an important factor in determining the response and tolerance during potentially injurious loading.

One previous study by Klein et al. ${ }^{15}$ developed parametric statistical models of femur geometry for use in developing FE femur models that are parameterized with occupant characteristics. In this current study, statistical models from the previous study that describe variations in femur geometry with age, femur length, and BMI for men and women were updated from additional CT scan geometry. A subsequent principal component analysis and regression (PCAR) analysis was used to generate updated statistical models of femur geometry. The predictions of the new statistical models were compared to the original model predictions. 


\section{Materials and Methods}

\subsection{Geometry Extraction}

The methods described here follow the same methods as used by Klein et al. ${ }^{15}$. Clinical CT scans of male and female lower extremities were obtained from the University of Michigan Department of Radiology through a protocol approved by an institutional review board at the University of Michigan. The CT scans were collected using a resolution of 512 x 512 pixels with $1.25 \mathrm{~mm}$ between slices. The inplane resolution varied from $0.625 \mathrm{~mm}$ to $0.977 \mathrm{~mm}$ across studies. As shown in Figure 1, the updated patient age range was 17-89 years, femur length $383 \mathrm{~mm}$ to 536 $\mathrm{mm}$, and BMI $15-48 \mathrm{~kg} / \mathrm{m}^{2}$. Figure 1 shows that no predictor (age, BMI, femur length) was highly correlated with another for men and women. Femur length is defined as the distance along the long axis of the femur (determined from anatomic landmark locations in the landmarking process) between the most superior point on the femoral head and most inferior point on the femoral condyles, and is shown in Figure 2.
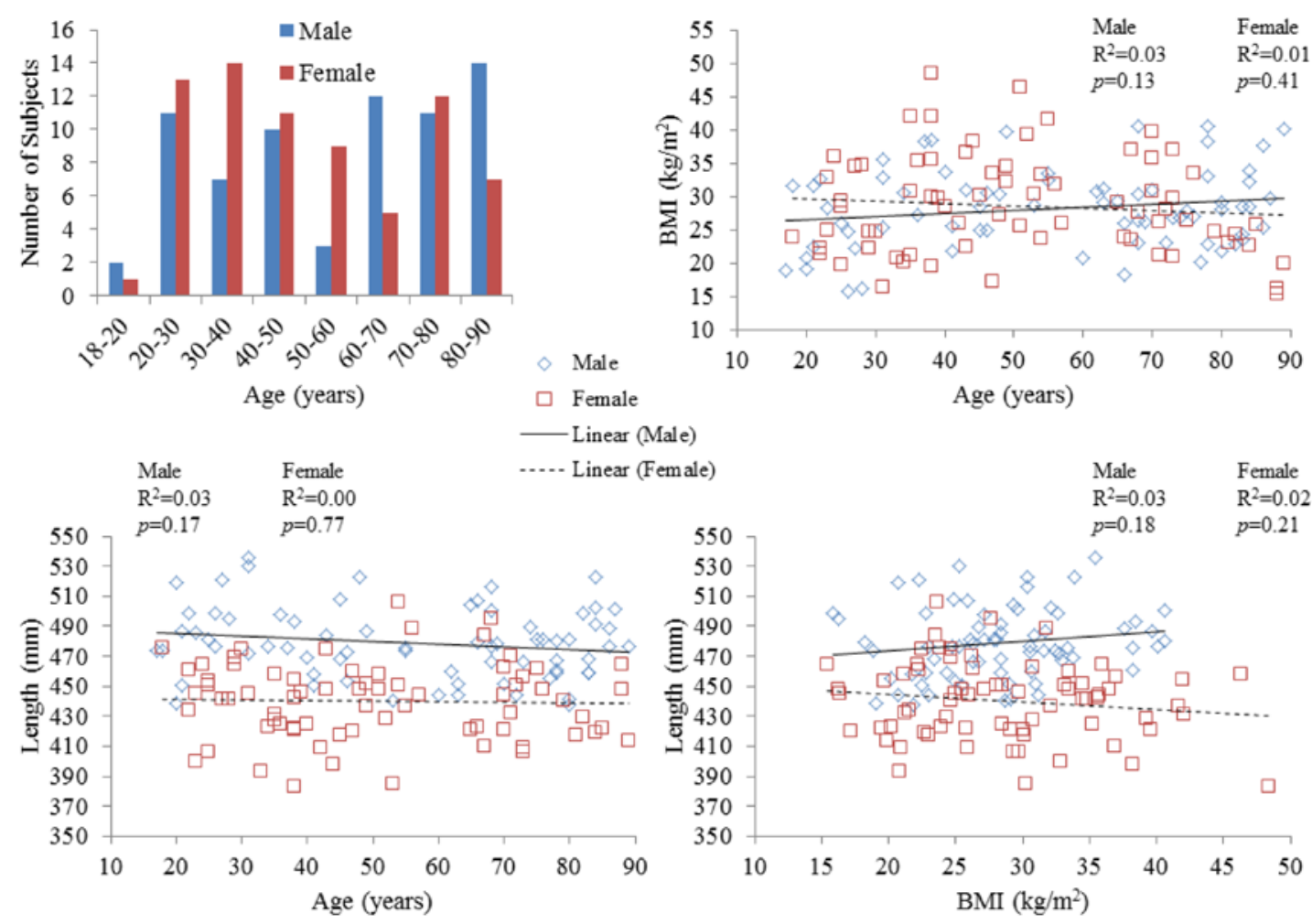

Figure 1. Distributions of subject characteristics. 


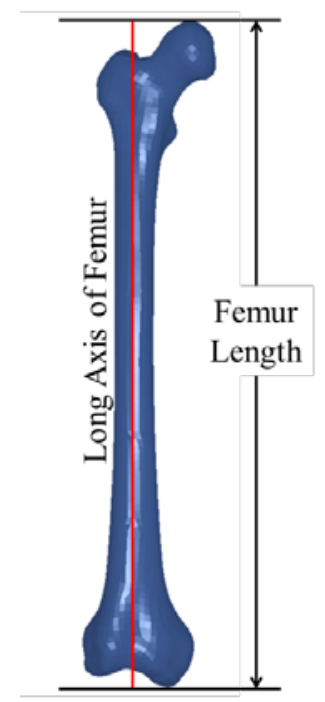

Figure 2. Femur length defined as the distance along the long axis of the femur (determined from anatomic landmark locations in the landmarking process) between the most superior point on the femoral head and most inferior point on the femoral condyles.

Thirty-six female and sixty-two male right femurs were segmented and 3D surfaces were extracted using OsiriX (Pixmeo, Switzerland) in the original study ${ }^{15}$. An additional thirty-six female and eight male right femurs were extracted for this study. The 3D volume rendering mode was used for surface extraction with a Hounsfield Unit threshold value of 300 , which was a value sufficiently low enough to capture detailed bone surface geometry. The coordinates of 13 easily distinguishable anatomic landmarks, such as the most lateral point on the greater trochanter, were manually digitized in Rhinoceros 3D (Robert McNeel \& Associates, Seattle, WA). The locations of an additional 46 landmarks were calculated programmatically from the locations of the original 13 landmarks. All 46 landmarks were determined using the locations of the 13 anatomic landmarks, and these 46 landmarks were calculated to account for regions with no anatomic landmarks. 36 landmarks were evenly distributed in medial/lateral and anterior/posterior directions along the shaft of the femur, and eight landmarks were on cross-sections of the femoral head and neck to account for the shape of these regions. The last two landmarks were midpoints of lines calculated from anatomic landmarks in the intertrochanteric region and in the neck region. The average difference in landmark locations identified by different observers who landmarked five of the same femurs was $3.8 \mathrm{~mm}$.

\subsection{Morphing and Fitting Processes}

Figure 3 illustrates the processes for morphing and fitting a template femur FE mesh onto extracted bone surface geometries. The template mesh comes from the right femur of the Total Human Model for Safety (THUMS) version $4^{32}$. The first step in the morphing process involved landmarking the template mesh with the same landmarks that were digitized for the extracted femur geometries. These landmarks were manually reviewed to ensure the locations were the same as for the extracted 
femur geometries. The nodal coordinates from the template mesh were then morphed into the approximate geometry of each femur using the landmarks on the template mesh and the extracted femur surface geometries. Morphing was performed using a thin-plate spline function for radial basis function morphing ${ }^{1,6}$. Next, the morphed meshes were fitted to the surface of each patient's bone to match the patient femur geometry. Using a method similar to the one described in Reed et al. ${ }^{27}$, the template nodes were moved to the extracted bone surface using an implicit surface

methodology.

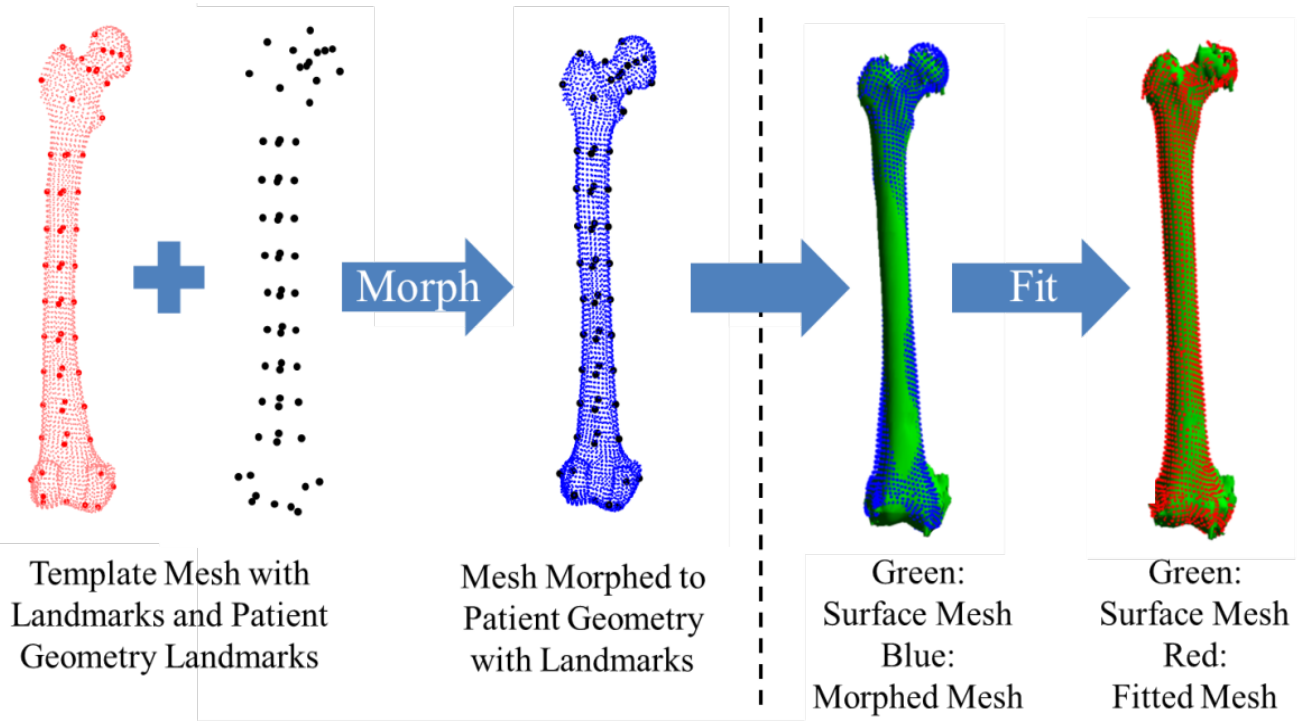

Figure 3. The morphing and fitting processes of a template femur FE mesh onto an example extracted bone surface geometry.

\subsection{Cortical Bone Thickness Calculation}

The inner surfaces of cortical bone were extracted from the original CT scans in a similar method as for the outer surface using a calculated threshold value determined for each femur to extract only the cortical bone. The outer surface normals were calculated at each nodal coordinate, and thickness values were determined based on distances between the outer and inner surfaces along the normal direction. If the thickness value was found to be zero at a nodal location, which occasionally happened near the condyles or the head, an average value from the eight closest points to the node was used to ensure all nodes had a non-zero value. In addition, if the thickness value fell below the $1.25 \mathrm{~mm}$ minimum value, the value was set to 1.25 $\mathrm{mm}$ in those locations.

\subsection{Principal Component Analysis and Regression}

The updated statistical models of femur external surfaces and thicknesses at nodal locations for men and women were developed using the same PCAR techniques ${ }^{12,} 26$ as the previous study ${ }^{15}$. The principal component analysis method used here follows the method discussed by Li et al. ${ }^{17}$. The coordinates of the fitted template meshes for all additional subjects, as well as original subjects, were rigidly aligned using 
Procrustes alignment and rescaling ${ }^{31}$. Principal component (PC) scores were computed based on the covariance of a geometry matrix obtained by flattening the concatenated coordinates of the mesh nodes for the external geometry models and the node thickness values for the thickness models. A regression analysis was performed following the procedure used in Reed et al. ${ }^{27}$ to predict PC scores from subject characteristics. PC scores were used to reconstruct femur geometry and nodal thicknesses. Femur nodal locations and the associated cortical thickness values were predicted using this regression analysis as functions of age, BMI, and femur length (which strongly correlates with stature) with separate models for men and women. In addition, the thickness models used significant PC scores from the geometry models as potential predictors in their regression functions due to the possible effects of external geometry on thickness. Right femurs were predicted and used in this study because the FE models that will eventually be used are symmetric and left femurs can be determined from reflecting the femur. The PCAR models use the same number of PC scores as number of subjects used to develop the models (72 for women and 70 for men). These numbers of PCs cover more than $99 \%$ of the variance in the data.

Evaluating the fit of regression models predicting PC scores is of minimal value because the data is no longer in its original coordinate system. Instead, goodness of fit was investigated by assessing the improvement in femur geometry prediction obtained when using the regression model rather than the average femur. External surface geometry and cortical bone thickness were compared between the femur data used to develop the statistical model and the femurs predicted using the original data's characteristics. In addition, model predictions were compared to extracted geometry from a different set of cadaver femurs ${ }^{11}$. Cortical bone areas were calculated for the predicted femurs and the cadaver femurs at five evenly spaced locations along the shaft of the right femur. These five locations along the femur and the definition of cortical bone area are shown in Figure 4. Location 1 is located at $25 \%$ of the total femur length below the most superior point on the femur and location 5 is located at $25 \%$ of the total femur length above the most inferior point. Locations 2, 3, and 4 are spaced evenly between locations 1 and 5.

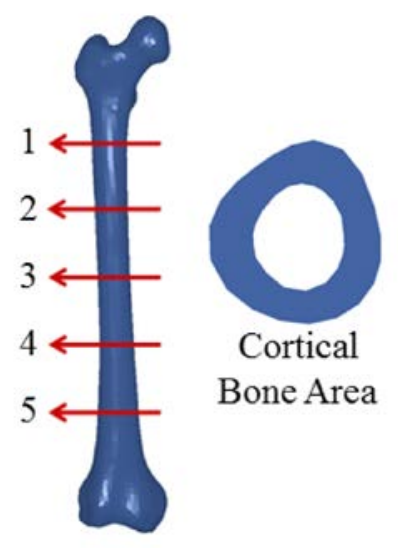

Figure 4. The five area locations (1-5) along the shaft of the femur used for cortical bone area measurements. 


\section{Results}

\subsection{Principal Component Analysis and Regression}

Overall $\mathrm{R}^{2}$ values for the external geometry models and thickness models were calculated using Equation 1, where the residual sum of squares was the sum of squared errors between the observed and predicted coordinates or thicknesses, and the total sum of squares was the sum of squared differences between the observed coordinates and average of each femur coordinate or the observed thickness values and the average of each thickness value. The overall calculated $\mathrm{R}^{2}$ values for the updated male and female femur external geometry models were 0.77 and 0.82 , respectively, and the original $R^{2}$ values were 0.77 and 0.74 . The overall calculated $R^{2}$ values are 0.57 and 0.58 for the male and female thickness models, respectively. The p-values from analysis of variance tests for the predictors on the first five principal components for the male and female external geometry models and thickness models are shown in Tables $1 \mathrm{a}$ and $1 \mathrm{~b}$, respectively. The predictors used in the analysis of variance test for the geometry models were age, femur length, and BMI, while the predictors used for the thickness models were age, BMI, and significant PC scores from the geometry model. Femur length was the most significant predictor for the male and female external geometry models, while no single parameter was the most significant predictor for the male and female thickness models.

$$
R^{2}=1-\frac{\text { Residual sum of squares }}{\text { Total sum of squares }}
$$

Equation 1. $\mathbf{R}^{2}$ value calculation.

Table 1a. $p$-values of predictors in the female and male external geometry models.

\begin{tabular}{|c|c|c|c|c|c|c|}
\hline \multirow{2}{*}{ Predictor } & \multicolumn{5}{c|}{$p$-value } \\
\cline { 2 - 7 } & 1st PC & 2nd PC & 3rd PC & 4th PC & 5th PC \\
\hline \multirow{3}{*}{$\begin{array}{c}\text { Female } \\
\text { Geometry }\end{array}$} & Age & 0.171 & 0.136 & 0.563 & $0.000^{*}$ & 0.969 \\
\cline { 2 - 7 } & Femur Length & $0.000^{*}$ & 0.089 & 0.593 & 0.845 & 0.465 \\
\cline { 2 - 7 } & BMI & $0.003^{*}$ & $0.003^{*}$ & 0.511 & $0.040 *$ & $0.017 *$ \\
\hline \multirow{3}{*}{$\begin{array}{c}\text { Male } \\
\text { Geometry }\end{array}$} & Age & 0.176 & $0.017 *$ & $0.000^{*}$ & 0.744 & 0.083 \\
\cline { 2 - 7 } & Femur Length & $0.000^{*}$ & 0.572 & 0.440 & 0.560 & 0.722 \\
\cline { 2 - 7 } & BMI & 0.229 & 0.174 & 0.477 & 0.557 & 0.108 \\
\hline \multirow{7yyyyyy}{*}{$* p<0.05$} & & & & \\
\hline
\end{tabular}

Table 1b. p-values of predictors in the female and male thickness models.

Predictor

\begin{tabular}{|l|l|l|l|l|}
\hline \multicolumn{4}{|c|}{$p$-value } \\
\hline 1st PC & 2nd PC & 3rd PC & 4th PC & 5th PC \\
\hline
\end{tabular}




\begin{tabular}{|c|c|c|c|c|c|c|}
\hline \multirow{5}{*}{$\begin{array}{c}\text { Female } \\
\text { Thickness }\end{array}$} & Age & $0.001^{*}$ & $0.014^{*}$ & 0.312 & $0.005^{*}$ & 0.300 \\
\cline { 2 - 7 } & BMI & 0.081 & 0.670 & 0.442 & $0.022^{*}$ & 0.433 \\
\cline { 2 - 7 } & Geometry PC Score 2 & 0.964 & 0.509 & $0.000^{*}$ & $0.022^{*}$ & 0.123 \\
\cline { 2 - 7 } & Geometry PC Score 3 & 0.868 & 0.289 & $0.000^{*}$ & $0.000^{*}$ & 0.692 \\
\cline { 2 - 7 } & Geometry PC Score 4 & 0.103 & $0.046^{*}$ & $0.000^{*}$ & 0.205 & 0.647 \\
\cline { 2 - 7 } & Geometry PC Score 6 & 0.333 & 0.402 & $0.000^{*}$ & 0.508 & 0.680 \\
\cline { 2 - 7 } & Geometry PC Score 7 & $0.008^{*}$ & 0.865 & $0.000^{*}$ & 0.650 & 0.437 \\
\cline { 2 - 7 } Male & Geometry PC Score 9 & 0.756 & 0.778 & $0.000^{*}$ & 0.237 & $0.029 *$ \\
\cline { 2 - 7 } & Geometry PC Score 10 & 0.837 & 0.169 & $0.001 *$ & 0.328 & 0.524 \\
\cline { 2 - 7 } & Age & $0.003 *$ & 0.334 & 0.859 & 0.079 & 0.989 \\
\cline { 2 - 7 } & Geometry PC Score 2 & $0.033^{*}$ & 0.811 & 0.605 & 0.475 & 0.404 \\
\cline { 2 - 7 } & Geometry PC Score 6 & 0.409 & 0.239 & 0.541 & 0.950 & 0.370 \\
\cline { 2 - 7 } & Geometry PC Score 7 & 0.059 & 0.599 & 0.436 & $0.019 *$ & 0.756 \\
\hline
\end{tabular}

The average absolute errors in male and female external surface geometry model predictions were $4.58 \mathrm{~mm}$ and $4.21 \mathrm{~mm}$, and the average absolute errors in male and female thickness model predictions were $1.17 \mathrm{~mm}$ and $0.97 \mathrm{~mm}$. The average distance errors and $95^{\text {th }}$ percentile errors in nodal coordinate locations between the fitted meshes to the actual data and the predicted meshes were calculated, and the distributions of errors in the bone can be seen for both the male and female models in Figure 5. The average and $95^{\text {th }}$ percentile absolute differences between the actual thicknesses and predicted thicknesses were also calculated, and the distributions of differences are shown in Figure 5. For both nodal coordinates and thickness errors, the larger errors occur in the ends of the femur, as was the case for the original models. The residuals for each model were checked for normal distributions and no trends were seen with any model predictor. 

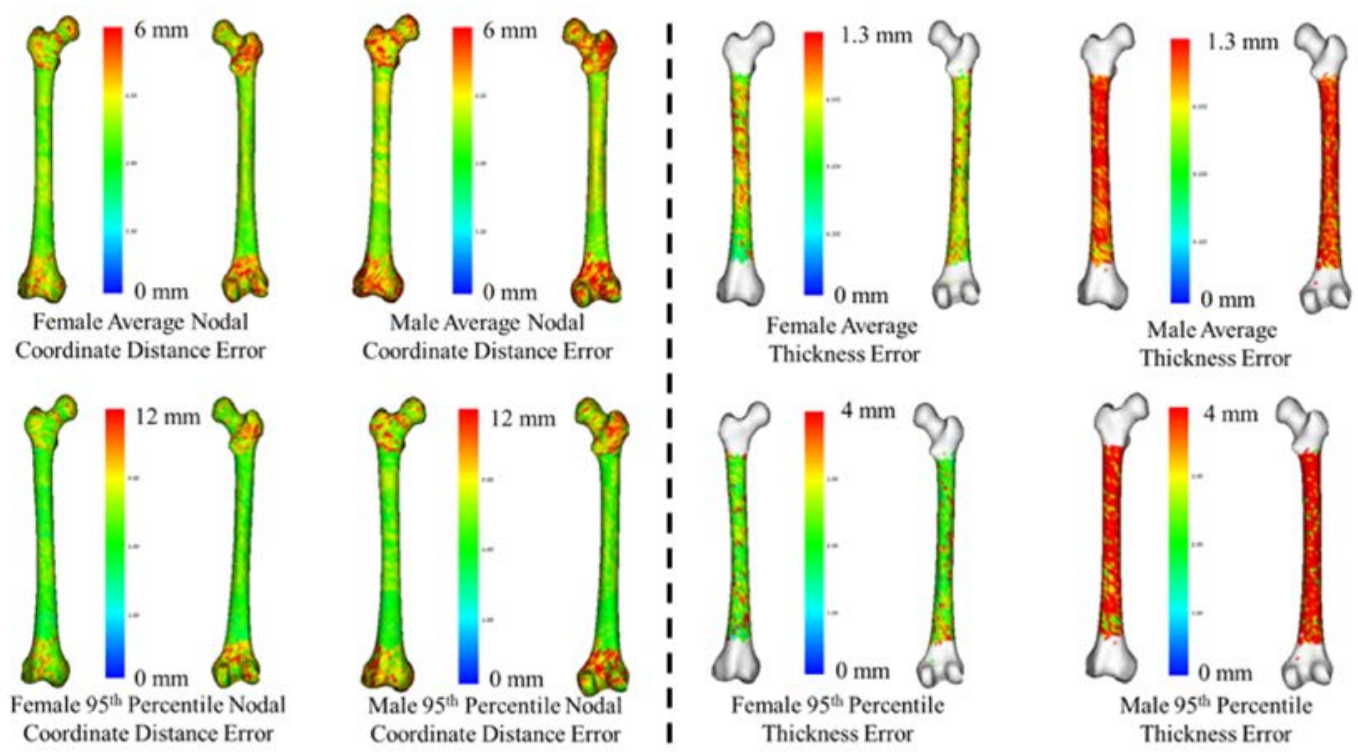

Figure 5. Distribution of average and $95^{\text {th }}$ percentile absolute errors in nodal coordinate locations (left two columns) and cortical thickness values at nodal locations (right two columns) between the actual data and predicted geometries.

The average Euclidean distance error in nodal coordinate locations based on the morphed template nodes between the 13 predicted shaft geometries from the statistical models and the shaft geometries from the CT scans of the Ivarsson et al. ${ }^{11}$ study after alignment using Procrustes alignment and rescaling was $4.7 \mathrm{~mm}$. When the femur shaft geometry predicted from the average subject characteristics was compared to each shaft, the average Euclidean distance error was $6.1 \mathrm{~mm}$. The difference between the predicted error and average error indicates that predicting geometry using subject characteristics more closely matches real geometry than the average models normally used. The average error in midshaft cross-sectional cortical bone area between the predicted geometries and the PMHS geometries was 12\%, and the average error between the predicted areas and the PMHS areas across the 5 locations was $17 \%$. The errors in cortical bone area calculated at 5 different locations along the shaft between the actual shafts and the predicted shafts are given in boxplots in Figure 6 with the mean error indicated. 


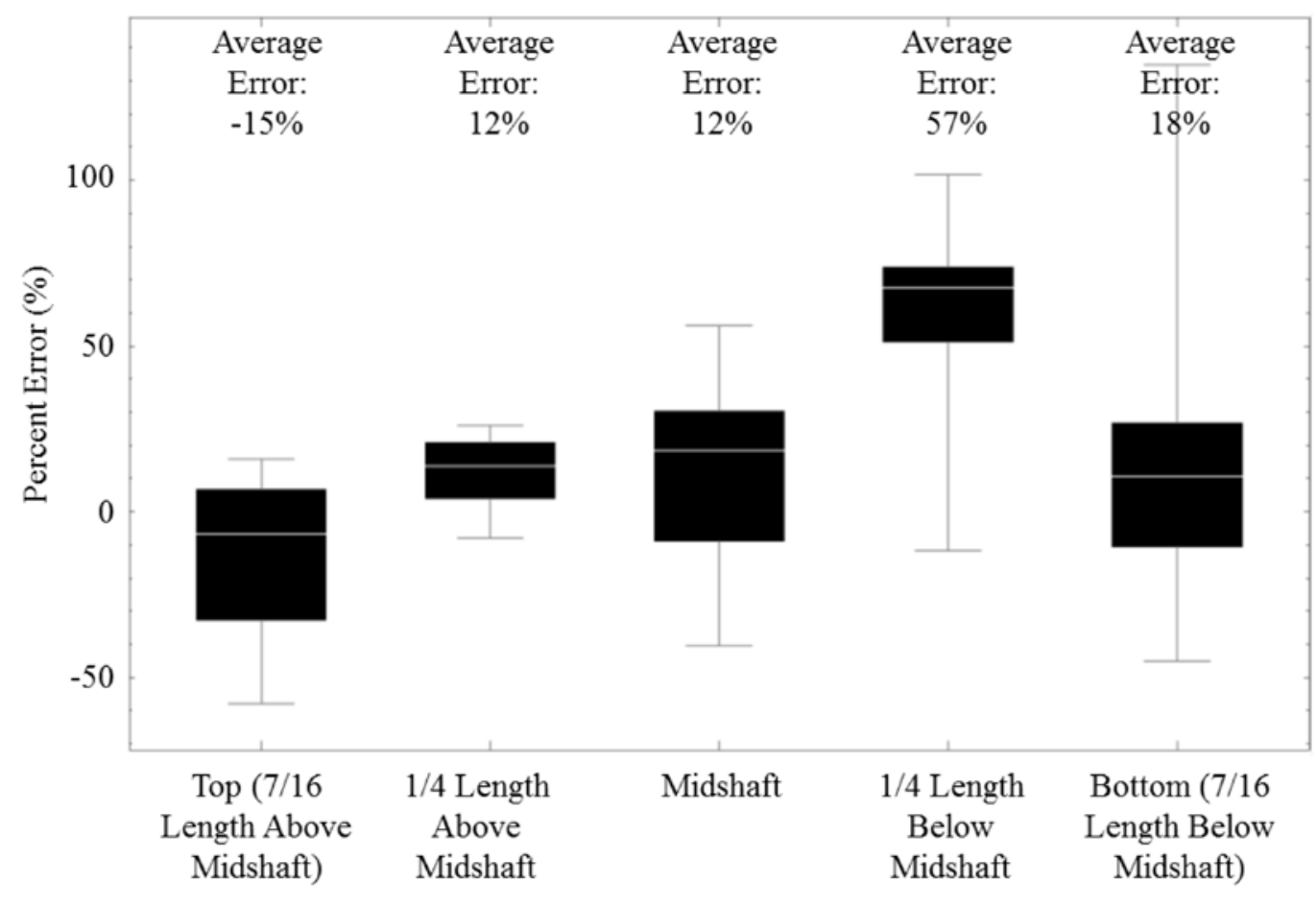

Shaft Location

Figure 6. Cortical bone cross-sectional areas at five locations along the shafts of the PMHS femurs and the errors in the predicted shaft cross-sectional areas.

The 13 new predicted femurs using the characteristics from the Ivarsson et al. ${ }^{11}$ study were compared to the original predicted femurs by looking at the Euclidean distance errors in the nodal coordinates between each subject and the differences in thickness values between each subject. The minimum, mean, and maximum distributions of these values are shown in the heat maps in Figure 7. The mean differences were small for both the nodal and coordinates and thicknesses (less than $2 \mathrm{~mm}$ ), and most of the differences appear at the ends of the femurs where the model predictions had the largest errors. 

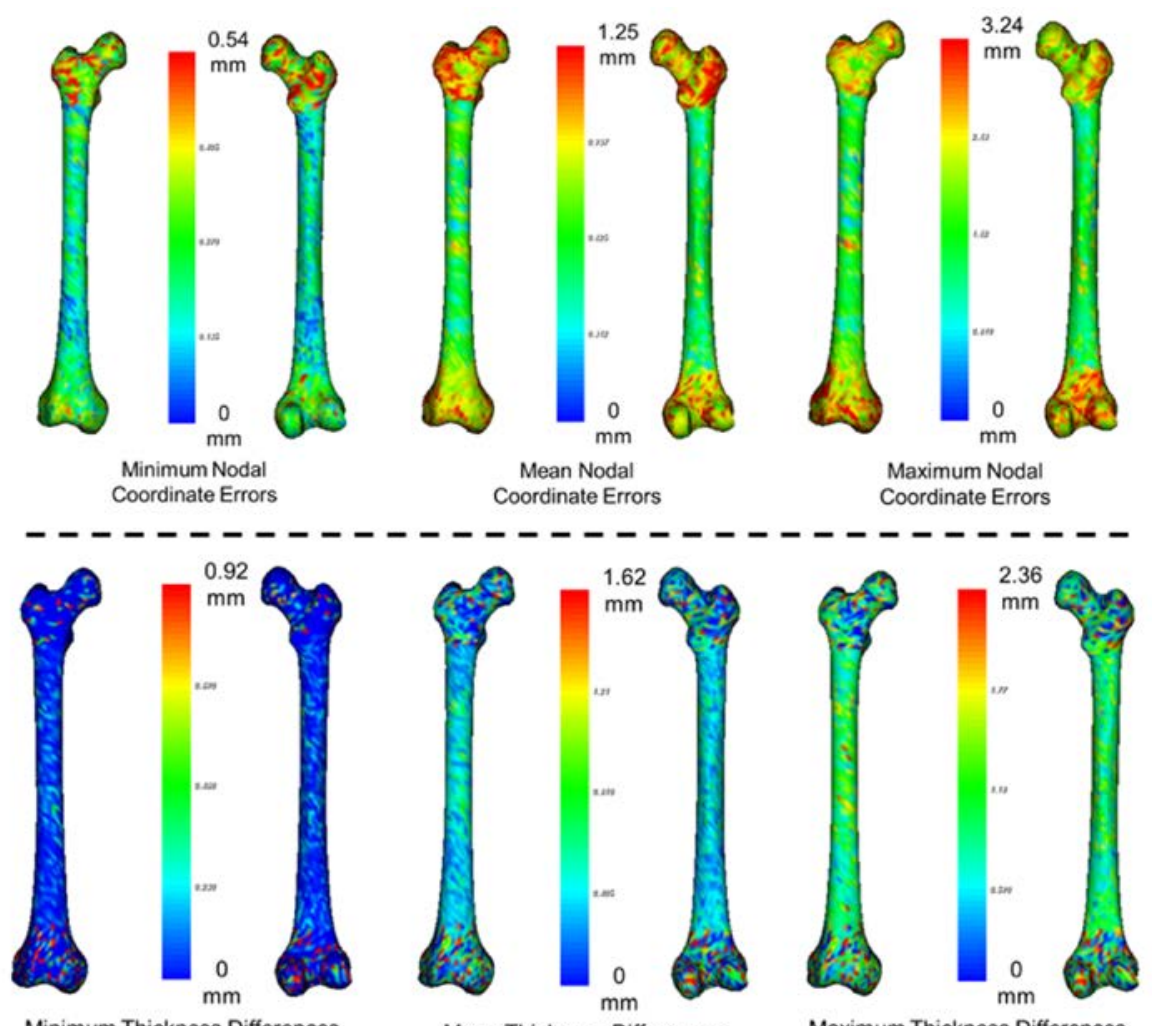

Mean Thickness Differences

Maximum Thickness Differences

Figure 7. Minimum, mean, and maximum distributions of nodal coordinate distance errors (top) and differences in thickness values (bottom) between original predicted femurs and updated predicted femurs using Ivarsson et al. ${ }^{11}$ study characteristics. 


\section{Discussion}

Statistical models of femur surface and cross-sectional geometry were updated based on additional CT data from 36 female and 8 male femurs for a total of 72 female and 70 male femurs. PCAR models were used to investigate the variation in femur geometry with subject parameters to better understand the effects of the parameters. The PCAR models describe the variance in femur shape with a small number of PCs well representing the data in orthogonally independent directions. The new model predictions were compared to original model predictions, and errors between the models were small with most error in the ends of the femur where the largest errors in predictions occur. The statistical models are readily implemented to enable rapid generation of geometries associated with a particular set of subject characteristics. Distance error distributions and thickness error distributions were determined in this study to represent differences between observed and predicted values; however, it is difficult to determine the meaning of the values of error and whether these values are low enough. A comparison of outputs of FE simulations using geometries predicted by the femur geometry models to experimental data will provide a more useful measure of model adequacy.

The male and female external surface geometry models were able to predict the overall geometry with relatively high $\mathrm{R}^{2}$ values, but the thickness models had lower $\mathrm{R}^{2}$ values. This indicates that overall size and shape of the femur are substantially accounted for by the model predictors of subject age, femur length, and BMI, but the variations in thickness are not well explained by these predictors or geometric features captured by the geometry PC model. It is possible that variation in thickness could be better explained if other predictors were used, such as the presence of diseases (e.g. osteoporosis). In addition, the models can best predict the geometry at values closest to the average values of the parameters and predict geometry least well at the extreme ends of the parameter values, as is expected. Since the models are simple linear regressions, the results are not much affected by leaving out a single point, as could be done in a leave-one-out cross-validation.

Separate statistical models were developed for external geometry and thickness, as well as men and women, to account for the different types of variation in geometry due to external shape and cross-sectional shape. The thickness models used age, BMI, and significant PC scores from the external geometry models as predictors to account for covariance between external geometry and thickness values (or internal geometry). A PCAR analysis was performed with the external geometry and thickness values combined, but no meaningful differences were seen in the results compared to the PCAR with separate models. Therefore, the separate external geometry and thickness models were used instead of a combined method since the benefits of using separate external geometry and thickness models include improved prediction of thickness values and better mesh quality for the nodal coordinates.

PCAR was used in this study instead of multiple regressions for three reasons: (1) the principal modes can be explored in the data set to aid in the understanding of the 
geometric variance, (2) the number of modes of variance (PCs) that are significantly related to potential predictors can be quantified, and (3) the orthogonality of the PCs can be exploited, along with the approximate normality of the PC scores, to generate femurs that span a desired range of the population for future applications. In addition, PC scores were used as predictors for the thickness model to account for effects of outer surface geometry on bone thickness, rather than directly predicting thickness from subject descriptors. This enables an explicit linkage between geometry and thickness, even when the thickness in a particular region of the bone may not be related to overall subject descriptors.

The statistical femur models were investigated for errors in this study to ensure the models were valid. The outer surface geometries and thickness values were compared between predicted values and the underlying data set's values. In addition, areas at different cross-sections along the shaft were compared to the additional data set. The errors in areas were average errors with both positive and negative values kept when calculating the overall average for each location. This type of error calculation is more appropriate than absolute errors because the models are intended to be used to generate FE models representing the entire occupant population. These FE models will be based on the statistical model predictions and then simulations will be performed with this population of models. As long as the statistical model predictions are reasonable, and geometric error is not biased with respect to model parameters, then model predictions of population risk will be reasonable (assuming a reasonable material model).

The sample size for the female subjects was increased in this study to improve on the small sample size used in the previous study ${ }^{15}$. While the number of male subjects was also increased, the change in female subjects caused the only improvement seen in the model. The outer surface $\mathrm{R}^{2}$ value for the previous female models was 0.74 , and for the updated models it was 0.82 . This increase in $\mathrm{R}^{2}$ shows that including twice the number of subjects than the original model only has a small change in covering the variance seen in the subject data. In addition, the differences in nodal coordinates and thickness values were small between the original predicted femurs and new predicted femurs using the characteristics from the Ivarsson et al. ${ }^{11}$ study. These errors also only occur in the ends of the femur where the models prediction errors are the largest. Therefore, it is not necessary to add any more subjects to the sample size.

A limitation of this study is that cortical thickness values of zero sometimes resulted from the calculation method due to the resolution of the CT scans. In addition, a minimum value had to be used as a cutoff in the ends of the femurs. Cortical bone thickness was similar to the CT scan slice size in certain areas, and, as a result, the cortical thickness could not be accurately calculated. These zero values and inaccurate values occurred at several points in the ends of the femurs (femoral head, neck, and condyles). However, the inherent problem with the resolution of clinical CT scans did not affect the shafts of the femurs, where thickness values were robustly calculated. An average value from the eight closest nodes to the node with zero value 
was used instead to allow for the models to have cortical bone in all locations, which is particularly important for finite-element modeling using solid elements.

The models developed in this study do not consider variations in bone density and the relationships between these variations in material properties. Such variations have been shown to be important in predicting the risk of hip fracture ${ }^{3}$. Parametric material models could be generated using methods similar to those described in studies by Keaveny et al. ${ }^{13}$, Keyak and Falkenstein ${ }^{14}$, Heaney ${ }^{9}$, and Nalla et al. ${ }^{22}$, and by Bredbenner et al. ${ }^{3}$, where CT scan data can be used to determine relationships between density and material properties at all locations on the bone. Future work should consider relationships between bone density and material properties when developing parametric material models for parametric FE models.

Femur length is used as a predictor in statistical models developed in this study as a surrogate for stature. Relationships between stature and femur length can be developed from existing datasets and used to reparameterize models so that stature is a predictor. However, using femur length as a predictor is advantageous as femur length can be determined from other existing statistical models that are useful for defining geometry targets for whole-body FE models as functions of age, BMI, and stature, such as driver posture prediction models and models of external body shape 20, 24, 25. This approach of using lengths determined from statistical models of whole body posture and external body shape that are parameterized based on stature, BMI, age, and sex ensures that geometries predicted by each of the statistical models are consistent, even if the models are based on different patient/occupant populations.

The methods for continued development of the statistical models that describe variations in femur geometry with age, femur length (as a function of stature), and BMI for men and women facilitate their use as part of a parametric lower-extremity model. This parametric lower-extremity model can eventually be used to investigate the effects of age, BMI, sex, and stature on lower-extremity injury in frontal crashes. An understanding of the effects of occupant characteristics on lower-extremity injury will allow for designing restraints to better protect vulnerable populations. 


\section{Acknowledgements}

This project was funded by the National Highway Traffic Safety Administration under contract number DTNH22-10-H-00288 and the National Science Foundation under award number 1300815 . The authors would like to thank Ms. Prabha Narayanaswamy for her support on the statistical analyses, the University of Virginia Center for Applied Biomechanics for their help in providing the CT scan data, Dr. Johan Ivarsson for providing the CT scan data, and the University of Michigan students who extracted femur geometry. 


\section{References}

1. Bennink, H. E., J. M. Korbeeck, B. J. Janssen and B. M. ter Haar Romeny. Warping a neuro-anatomy atlas on 3D MRI data with radial basis functions. Proc. International Conference on Biomedical Engineering 3: 214-218, 2006.

2. Besnault, B., F. Lavaste, H. Guillemot, S. Robin and J. Y. Le Coz. A parametric finite element model of the human pelvis. Proc. Stapp Car Crash Conference 42: P-337, 1998.

3. Bredbenner, T. L., R. L. Mason, L. M. Havill, E. S. Orwoll and D. P. Nicolella. Fracture risk predictions based on statistical shape and density modeling of the proximal femur. J Bone Miner Res 29: 2090-2100, 2014.

4. Bryan, R., P. S. Mohan, A. Hopkins, F. Galloway, M. Taylor and P. B. Nair. Statistical modelling of the whole human femur incorporating geometric and material properties. Med Eng Phys 32: 57-65, 2010.

5. Bryan, R., P. B. Nair and M. Taylor. Use of a statistical model of the whole femur in a large scale, multi-model study of femoral neck fracture risk. J Biomech 42: 21712176, 2009.

6. $\quad$ Carr, J. C., R. K. Beatson, J. B. Cherrie, T. J. Mitchell, W. R. Fright, B. C. McCallum and T. R. Evans. Reconstruction and representation of 3D objects with radial basis functions. Proc. Annual Conference on Computer Graphics and Interactive Techniques 28: 67-76, 2001. 
7. Carter, P. M., C. A. C. Flannagan, M. P. Reed, R. M. Cunningham and J. D. Rupp. Comparing the effects of age, BMI and gender on severe injury (AIS $3+$ ) in motorvehicle crashes. Accident Analysis and Prevention 72: 146-160, 2014.

8. Gayzik, F. S., M. M. Yu, K. A. Danelson, D. E. Slice and J. D. Stitzel. Quantification of age-related shape change of the human rib cage through geometric morphometrics. J Biomech 41: 1545-1554, 2008.

9. Heaney, R. P. Is the paradigm shifting? Bone 33: 457-465, 2003.

10. Hu, J., J. D. Rupp and M. P. Reed. Focusing on vulnerable populations in crashes: recent advances in finite element human models for injury biomechanics research. Journal of Automotive Safety and Energy 3: 295-307, 2012.

11. Ivarsson, B. J., D. Genovese, J. R. Crandall, J. R. Bolton, C. D. Untaroiu and D. Bose. The tolerance of the femoral shaft in combined axial compression and bending loading. Proc. Stapp Car Crash Conference 53: 251-290, 2009.

12. Joliffe, I. T. Principal component analysis. edited by Springer 2002.

13. Keaveny, T. M., P. F. Hoffmann, M. Singh, L. Palermo, J. P. Bilezikian, S. L. Greenspan and D. M. Black. Femoral bone strength and its relation to cortical and trabecular changes after treatment with PTH, alendronate, and their combination as assessed by finite element analysis of quantitative CT scans. J Bone Miner Res 23: 19741982, 2008. 
14. Keyak, J. H. and Y. Falkinstein. Comparison of in situ and in vitro CT scan-based finite element model predictions of proximal femoral fracture load. Med Eng Phys 25: 781-787, 2003.

15. Klein, K. F., J. Hu, M. P. Reed, C. N. Hoff and J. D. Rupp. Development and validation of statistical models of femur geometry for use with parametric finite element model. Ann Biomed Eng 43: 2503-2514, 2015.

16. Kurazume, R., K. Nakamura, T. Okada, Y. Sato, N. Sugano, T. Koyama, Y. Iwashita and T. Hasegawa. 3D reconstruction of a femoral shape using a parametric model and two 2D fluoroscopic images. Computer Vision and Image Understanding 113: 202-211, 2009.

17. Li, Z., J. Hu, M. P. Reed, J. D. Rupp, C. N. Hoff, J. Zhang and B. Cheng. Development, validation, and application of a parametric pediatric head finite element model for impact simulations. Ann Biomed Eng 39: 2984-2997, 2011.

18. Lu, Y. C., A. R. Kemper, F. S. Gayzik, C. D. Untaroiu and P. Beillas. Statistical modeling of human liver incorporating the variations in shape, size, and material properties. Proc. Stapp Car Crash Conference 57: 285-311, 2013.

19. Lu, Y. C. and C. D. Untaroiu. Statistical shape analysis of clavicular cortical bone with applications to the development of mean and boundary shape models. Comput Methods Programs Biomed 111: 613-628, 2013. 
20. Manary, M. A., M. P. Reed, C. A. C. Flannagan and L. W. Schneider. ATD positioning based on driver posture and position. Proc. Stapp Car Crash Conference 42: P-337, 1998.

21. Moran, S. G., G. McGwin, Jr., J. S. Metzger, J. E. Alonso and L. W. Rue, 3rd. Relationship between age and lower extremity fractures in frontal motor vehicle collisions. J Trauma 54: 261-265, 2003.

22. Nalla, R. K., J. J. Kruzic, J. H. Kinney and R. O. Ritchie. Effect of aging on the toughness of human cortical bone: evaluation by R-curves. Bone 35: 1240-1246, 2004.

23. Nicolella, D. P. and T. L. Bredbenner. Development of a parametric finite element model of the proximal femur using statistical shape and density modeling. Comput Methods Biomech Biomed Engin 15: 101-110, 2012.

24. Park, B. K., J. C. Lumeng, C. N. Lumeng, S. M. Ebert and M. P. Reed. Child body shape measurement using depth cameras and a statistical body shape model. Ergonomics 1-9, 2014.

25. Reed, M. P., S. M. Ebert and J. J. Hallman. Effects of driver characteristics on seat belt fit. Proc. Stapp Car Crash Conference 57: 43-57, 2013.

26. Reed, M. P. and M. B. Parkinson. Modeling variability in torso shape for chair and seat design. Proc. of the ASME Design Engineering Technical Conferences 1-9, 2008. 
27. Reed, M. P., M. M. Sochor, J. D. Rupp, K. D. Klinich and M. A. Manary. Anthropometric specification of child crash dummy pelves through statistical analysis of skeletal geometry. J Biomech 42: 1143-1145, 2009.

28. Ridella, S. A., A. Beyersmith and K. Poland. Factors associated with age-related differences in crash injury types, causation, and mechanisms. 2012.

29. Rupp, J. D. and C. A. C. Flannagan. Effects of occupant age on AIS 3+ injury outcome determined from analyses of fused NASS/CIREN data. 2011.

30. Shi, X., L. Cao, M. P. Reed, J. D. Rupp, C. N. Hoff and J. Hu. A statistical human rib cage geometry model accounting for variations by age, sex, stature and body mass index. J Biomech 47: 2277-2285, 2014.

31. Slice, D. E. Geometric morphometrics. Annual Review of Anthropology 36: 261281, 2007.

32. Toyota Motor Corporation. THUMS AM50 pedestrian/occupant model academic version 4.0. 2011. 